\title{
Impact of Overlapping Collector on Orientated Deposition of Electrospun Nanofibers
}

\author{
Changfu Fang ${ }^{1}$, Yan Jiang ${ }^{2}$ and Lei Xu ${ }^{*}, 1$ \\ ${ }^{1}$ School of Mechanical and Electric Engineering, Jingdezhen Ceramic Institute, Jingdezhen 333403, China \\ ${ }^{2}$ Power Lift Institute, Daqing Petroleum Equipment Group, Taicang 215400, China
}

\begin{abstract}
Standard electrospinning deposits disorderly nanofibers on a conducting collector owing to unstable whipping of the jet. Nevertheless, biological engineering requires orderly electrospun nanofibers to improve mechanical properties and cellular proliferation. An attempt is made to fabricate well-orientated nanofibers by applying an overlapping collector. It turns out that electrospinning deposits random and disorderly nanofibers as usual even if conducting aluminum foil, as a collector, overlaps insulating poly(ethylene terephthalate) (PET) film. When insulating PET film overlapping aluminum foil is applied as a collector, the PET film accumulates ions to repel the whipping filament in the space while nonoverlapping aluminum foil attracts the filament such that electrospinning deposits orientated nanofibers on the insulating PET film.
\end{abstract}

Keywords: Electrospinning, nanofiber, orientated deposition, patterned collector.

\section{INTRODUCTION}

As an efficient process to produce nanofibers, electrospinning has attracted much attention with the development of micro- and/or nanoscale manufacturing technologies in recent years. Electrospinning can fabricate planar and three-dimensional structures by applying polymeric, metallic, ceramic, and organic materials [1-4]. In laboratories, electrospinning has been widely used to produce composite nanofibers [5], filtering films [6], solar cells [7], microsensors [8], and tissue scaffolds [9].

In standard electrospinning, continuous solution supply results in a pendant adhering to the nozzle exit due to surface tension force. Electric charges are injected from the nozzle into solution and then transferred onto the pendant surface such that the pendant stretches into a cone shape under an applied electric force. A jet, carrying electric charges, issues from the pendant onto a collector once the electric force overcomes the surface tension force and viscous force. The jet has a stable segment adjacent to the pendant tip and an unstable segment. The unstable segment results from a primary instability, also called the spiral whipping, in the space and a secondary instability on the collector under interactions of electric charges [10]. With an evaporation of solvent and spiral extension, the jet grows thin and becomes a filament.

In biological engineering, applied orderly electrospun nanofibers are useful and valid to enhance cellular adherence and proliferation because of their advantages of large aspect ratio, structural uniformity, and better mechanical properties.

*Address correspondence to this author at the School of Mechanical and Electric Engineering, Jingdezhen Ceramic Institute, Taoyang Road, Jingdezhen 333403, China; Tel: +86-798-8465857;

E-mail: charlie1975@163.com
Nevertheless, standard electrospinning deposits random and disorderly nanofibers on the collector under instable whipping. This work discusses the effect of overlapping collector on the orientation of electrospun fibers.

\section{EXPERIMENT}

The experiment used a typical setup [11], in which a high-voltage power supply (Dongwen DW-P503) connects to a grounded collector and a stainless steel nozzle (o.d. = $0.41 \mathrm{~mm}$, i.d. $=0.21 \mathrm{~mm}$ ). A syringe pump (Ristron RSP01B) supplied the nozzle with 14 w.t. \% poly(ethylene oxide) $(\mathrm{PEO}, \mathrm{MW}=300,000 \mathrm{~g} / \mathrm{mol})$ solution. The nozzle-tocollector distance was $14 \mathrm{~cm}$; the applied voltage was $10 \mathrm{kV}$.

The applied collector utilized an overlapping configuration of 0.04-mm-thick aluminum foil and 0.2-mmthick poly(ethylene terephthalate) (PET) film. The upper layer was patterned and round inside but squared outside as shown in Fig. (1); the lower was rectangular and larger than the upper. The inside circle of upper patterned collector was $10 \mathrm{~mm}$ in diameter; the side length of outside square was 20 $\mathrm{mm}$. Measured nanofiber samples were extracted from specific locations: Points (A), (B), (C), and (D) on patterned collector.

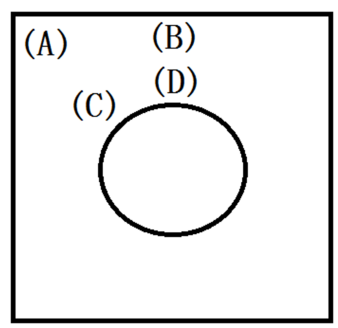

Fig. (1). The patterned collector on which nanofibers are extracted from specific locations: (A), (B), (C), and (D). 


\section{RESULTS AND DISCUSSION}

Fig. (2) shows nanofibers deposited on patterned aluminum foil with overlapping PET film. Fig. (2A-D) are SEM graphs of electrospun nanofibers extracted from corresponding locations of patterned aluminum foil as shown in Fig. (1). It is noted from the illustrations that all the fibers are disorderly as usual in standard electrospinning.

Although patterned aluminum foil, as a collector, overlaps with the insulating PET film, the upper aluminum foil is such a good conductor that electrospinning still has a preferential orientation of deposition on the conducting collector. Furthermore, Fig. (2A) further demonstrates that the quantity of deposited nanofibers at the corner of the aluminum design is fewer than the quantities at other locations, as the spiral whipping of filament results in little deposition at the corner.

Fig. (3) shows nanofibers deposited on the patterned PET film overlapping with the aluminum foil. Fig. (3A-D) are SEM graphs of electrospun nanofibers extracted from corresponding locations of patterned PET film as shown in Fig. (1). It is seen that the insulating PET film collects wellordered nanofibers in comparison with the conducting aluminum foil.

PET film accumulates a large number of ions due to its low conductivity and long relaxation time. These accumulated ions have such like polarity with those charges carried by the jet in the space that they repel the random deposition of nanofibers on the PET film. Aluminum foil at the bottom layer, on the other hand, is larger than the patterned PET film at the top layer. Non-overlapping aluminum foil, inside the circle and outside the square of PET design, attracts whipping filament due to the priorityof-conductivity principle during electrospinning. This attraction from both inside and outside of the design stretches the filament over the PET film. Hence, the patterned PET film collects more orderly nanofibers than patterned aluminum foil.

\section{CONCLUSION}

Standard electrospinning has a preferential deposition on a conducting collector. The priority-of-conductivity principle as well as the spiral whipping results in random and disordered deposition of electrospun nanofibers on a conducting collector, even if a conducting aluminum foil, as a collector, overlaps insulating PET film. Nevertheless, applied PET film can accumulate ions to repel charged jet in the space when it overlaps conducting aluminum foil. Largearea aluminum foil at the bottom layer of a collector stretches such filaments over the PET film such that electrospinning fabricates well-orderly nanofibers on insulating PET film.
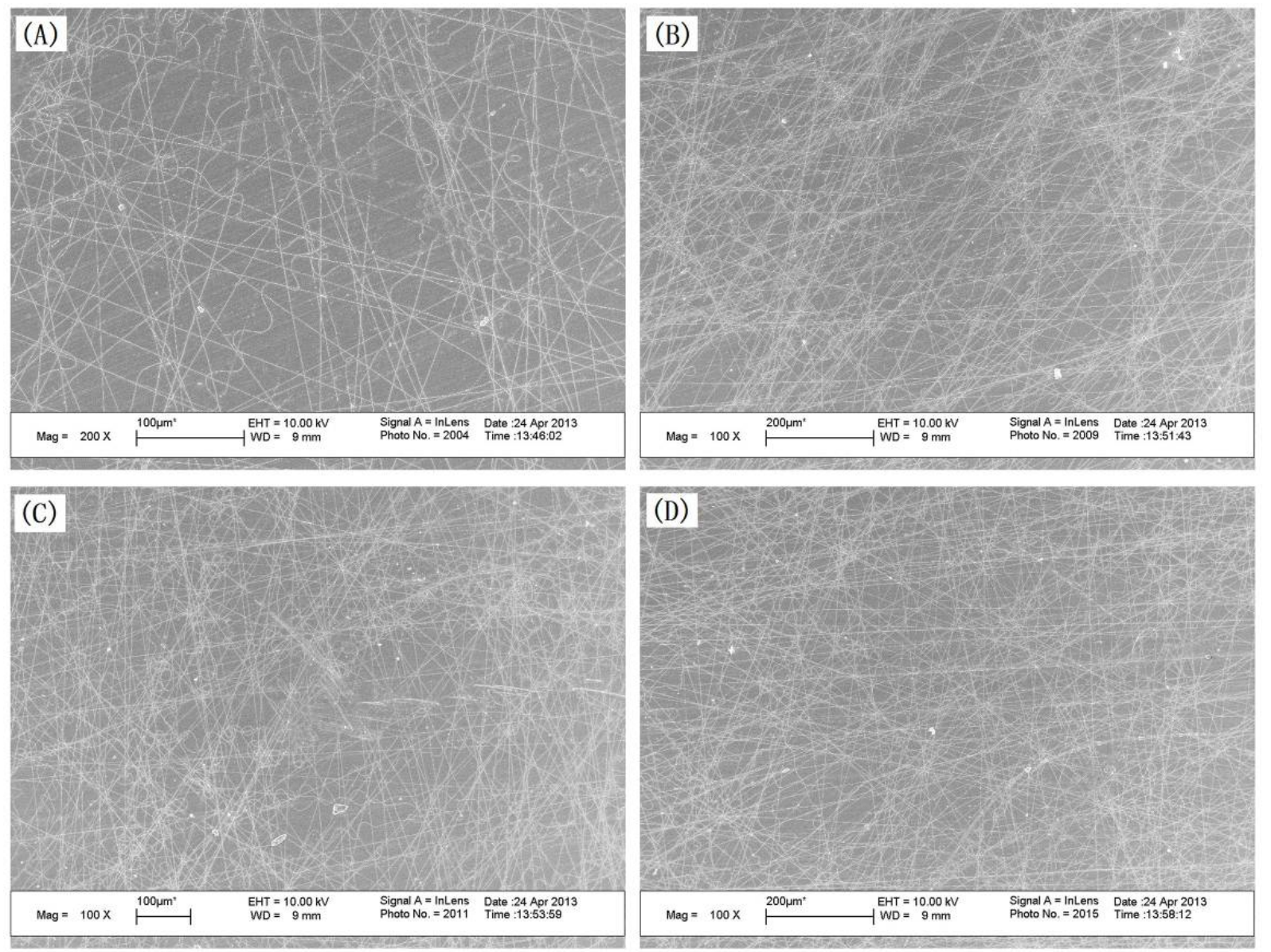

Fig. (2). SEM graphs of deposited nanofibers extracted from corresponding locations of patterned aluminum foil overlapping PET film: (A), (B), (C), and (D). 

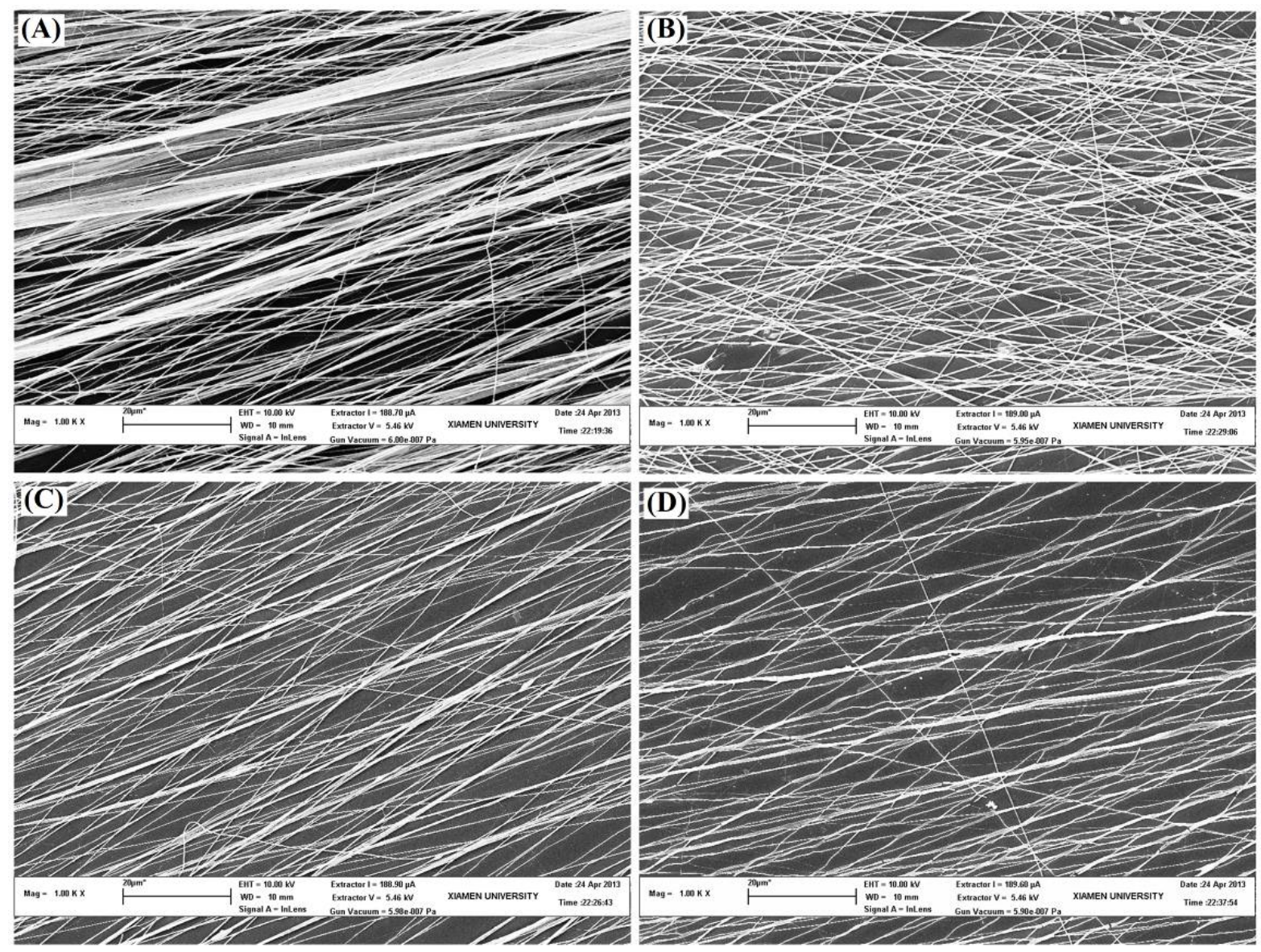

Fig. (3). SEM graphs of deposited nanofibers extracted from corresponding locations of patterned PET film overlapping aluminum foil: (A), (B), (C), and (D).

\section{CONFLICT OF INTEREST}

The authors confirm that this article content has no conflict of interest.

\section{ACKNOWLEDGEMENTS}

Project supported by the Foundation of Education Bureau of Jiangxi Province, China (GJJ13634).

\section{REFERENCES}

Persano L, Camposeo A, Tekmen C, Pisignano D. Industrial upscaling of electrospinning and applications of polymer nanofibers, A review. Macromol Mat Eng 2013; 298: 504-20.

[2] Hansen NS, Cho D, Joo YL. Metal nanofibers with highly tunable electrical and magnetic properties via highly loaded water-based electrospinning. Small 2012; 8: 1510-4.

[3] Wu H, Pan W, Lin D, Li H. Electrospinning of ceramic nanofibers: Fabrication, assembly and applications. J Adv Ceram 2012; 1: 223.

[4] Meinel AJ, Germershaus O, Luhmann T, Merkle HP, Meinel L. Electrospun matrices for localized drug delivery: Current technologies and selected biomedical applications. Eur J Pharm Biopharm 2012: 81: 1-13.

[5] Devarayan K, Hanaoka H, Hachisu M, et al. Direct electrospinning of cellulose-chitosan composite nanofiber. Macromol Mat Eng 2013; 298: 1059-64.

[6] Huang L, Manickam SS, McCutcheon JR. Increasing strength of electrospun nanofiber membranes for water filtration using solven vapor. J Membr Sci 2013; 436: 213-20.

[7] Park SH, Jung HR, Lee WJ. Hollow activated carbon nanofibers prepared by electrospinning as counter electrodes for dyesensitized solar cells. Electrochim Acta 2013; 102: 423-8.

[8] Zampetti E, Macagnano A, Bearzotti A. Gas sensor based on photoconductive electrospun titania nanofibers operating at room temperature. J Nanopart Res 2013; 15: 1566-74

[9] Dalton PD, Vaquette C, Farruqia BL, Dargaville TR, Brown TD, Hutmacher DW. Electrospinning and additive manufacturing: Converging technologies. Biomat Sci 2013; 1: 171-85.

[10] Reneker DH, Yarin AL, Fong H, Koombhongse S. Bending instability of electrically charged liquid jets of polymer solutions in electrospinning. J Appl Phys 2000; 87: 4531-47.

[11] Pillay V, Dott C, Choonara YE, et al. A review of the effect of processing variables on the fabrication of electrospun nanofibers for drug delivery applications. J Nanometer 2013; 2013: 22

(C) Fang et al.; Licensee Bentham Open.

This is an open access article licensed under the terms of the Creative Commons Attribution Non-Commercial License (http://creativecommons.org/licenses/ by-nc/4.0/) which permits unrestricted, non-commercial use, distribution and reproduction in any medium, provided the work is properly cited. 